Psychother Psychosom 2016;85:238-240

DOI: 10.1159/000442292

\title{
Brain and Behavior Changes following Exposure Therapy Predict Outcome at 8-Year Follow-Up
}

Iris Lange ${ }^{\mathrm{a}}$, Liesbet Goossens ${ }^{\mathrm{a}}$, Nicole Leibolda , Bram Vervliet ${ }^{\mathrm{b}}$, Stefan Sunaert ${ }^{c}$, Ronald Peeters ${ }^{c}$, Therese van Amelsvoort ${ }^{\mathrm{a}}$, Koen Schruers ${ }^{\mathrm{a}, \mathrm{b}}$

a Department of Psychiatry and Neuropsychology, School of Mental Health and Neuroscience, Maastricht University, Maastricht, The Netherlands; ${ }^{\mathrm{b}}$ Department of Psychology, University of Leuven, and ${ }^{\mathrm{C}} \mathrm{MR}$ Research Center, Department of Radiology, University Hospitals KU Leuven, Leuven, Belgium

Even the most effective psychological treatments, such as cognitive behavioral therapy, show high percentages of relapse in the long term [1]. Predicting the persistence of therapy effects remains a major unanswered question, which is complicated by psychiatric comorbidity and by limited insight into the effectiveness of different therapy components applied during cognitive behavioral therapy. Neuroimaging offers the possibility of objective measures for predicting long-term therapy success and to elucidate its mechanisms. A first step to disentangle the problem of predicting therapy persistence is to (1) investigate a phenotypically clear disorder like specific phobia and (2) choose one cognitive behavioral therapy component targeting a single therapeutic mechanism such as exposure therapy, the clinical application of extinction learning [1].

Here, we link behavioral and neural changes following exposure therapy for specific phobia with behavioral measures at 8-year follow-up, to investigate which outcome measures of short-term therapeutic assessment are associated with long-term persistence of therapeutic response.

Sixteen right-handed, unmedicated female spider phobic subjects received one prolonged ( $3-5 \mathrm{~h}$ ) session of group-based exposure therapy. The diagnosis of specific phobia was made by an experienced psychiatrist (K.S.) based on DSM-IV criteria. Any further psychopathology was excluded by means of a structured psychiatric interview. Subjects were scanned twice, 1 week before (T0) and 2 weeks after therapy (T1), while undergoing a symptom provocation functional magnetic resonance imaging (fMRI) paradigm. Behavioral ratings at T0 and T1 consisted of phobia severity (Spider Phobia Questionnaire, SPQ) and fear/arousal for spiders [2]. At 8 years of follow-up, 15 subjects agreed to participate in the follow-up study and rated phobia severity on the SPQ again. The

\section{KARGER}

E-Mail karger@karger.com www.karger.com/pps

\section{(9) 2016 The Author(s) \\ Published by S. Karger AG, Basel 0033-3190/16/0854-0238\$39.50/0}

This article is licensed under the Creative Commons AttributionNonCommercial-NoDerivatives 4.0 International License (CC BYNC-ND) (http://www.karger.com/Services/OpenAccessLicense). Usage and distribution for commercial purposes as well as any distribution of modified material requires written permission. local ethics committee approved the study, and written consent was obtained.

Behavioral change was examined with repeated measures analyses of variance. Short-term behavioral changes (T1-T0) were correlated with long-term outcome (SPQ). For the fMRI analyses in SPM8, we first created individual contrast images for spider $>$ neutral, followed by statistical images of therapy-related change (T1T0). A second-level regression analysis was used to evaluate baseline and changes (T1-T0) in neural activation associated with follow-up SPQ scores. A familywise error rate small-volume correction was applied for a priori regions of interest: left amygdala, anterior cingulate cortex, and left insula, as these regions showed therapy-induced changes [2]. Additionally, an exploratory whole-brain second-level analysis was conducted.

Figure 1 shows an overview of the behavioral and neural results. Although SPQ scores at follow-up were increased compared to SPQ scores at $\mathrm{T} 1(\mathrm{p}<0.01)$, they were still lower than T0 ratings $[\mathrm{F}(1.37,19.19)=57.342 ; \mathrm{p}<0.001 ;$ post hoc $\mathrm{p}<0.001]$, indicating that the therapy effect was partially maintained over 8 years. Furthermore, SPQ and fear/arousal score reductions from pre- to posttherapy assessments (T1-T0; $\mathrm{r}=0.78, \mathrm{p}<0.01 ; \mathrm{r}=0.57, \mathrm{p}<$ $0.05 ; \mathrm{r}=0.70, \mathrm{p}<0.01)$ were associated with a lower SPQ score at follow-up. Similarly, a lower SPQ score at follow-up was associated with more attenuation in the BOLD response from pre- to posttherapy time points (T1-T0) in the left anterior insula (cluster extending into the lateral orbitofrontal cortex, peak voxel MNI coordinates $-26 / 24 /-12$, cluster size $=29$ voxels, $t=7.20, p<0.01$, $r=0.89$ ). This effect was not driven by changes in processing of neutral images between T0 and T1. Change in activation (T1-T0) in other brain regions did not correlate with the follow-up SPQ scores, as tested by the small-volume correction analysis and whole-brain analysis. To check whether the observed associations were driven by $\mathrm{T} 1-\mathrm{T} 0$ variance, we further tested whether associations existed between the follow-up SPQ score and behavioral and neural data at T0 and T1. We only found a correlation with the T1 SPQ score and the follow-up SPQ score $(\mathrm{r}=0.91, \mathrm{p}<$ $0.001)$.

In conclusion, the present findings show strong negative correlations between phobia severity at the 8-year follow-up and changes (T1-T0) in anterior insula activation and fear scores. Recently, it has been argued that symptom reduction directly following exposure therapy for phobia is only weakly predictive of treatment outcome [3]. The present findings, however, point to the usefulness of assessing fear levels in the evaluation of the therapy effect when not measured immediately after therapy, but after allowing time for consolidation of learning.

The demonstrated association between the extent of insular activity reduction and better clinical outcome at 8 years of follow- 


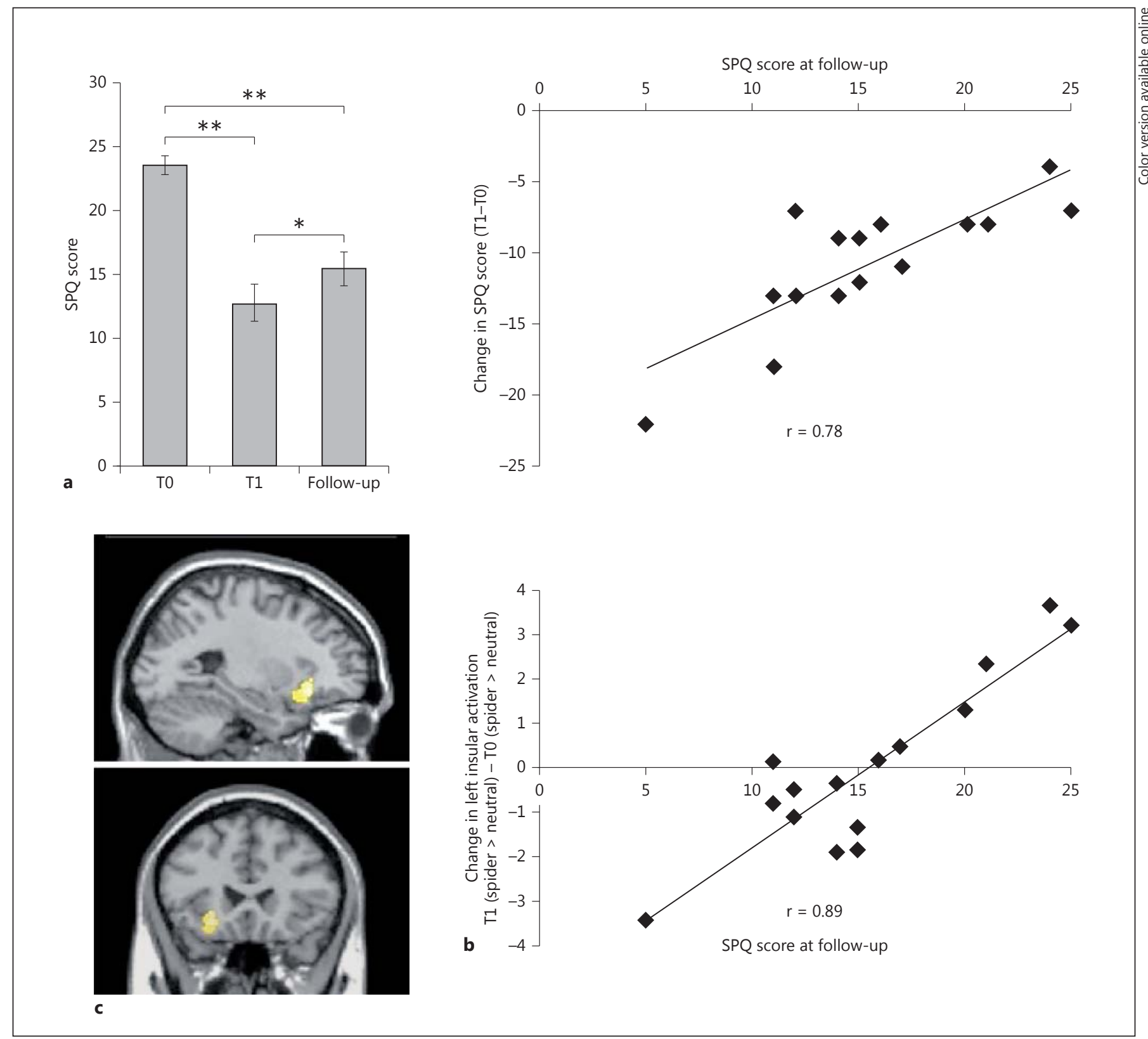

Fig. 1. Results of the study. a SPQ scores at the pretherapy scanning session (T0), posttherapy scanning session (T1), and at the 8-year follow-up. Bars represent means \pm SEM. ${ }^{*} \mathrm{p}<0.05,{ }^{* *} \mathrm{p}<0.01$. b Correlation between reduction in SPQ scores from T0 to T1 and SPQ score at follow-up. c Change in left insula, extending into the lateral orbitofrontal cortex, at peak voxel coordinates $(-26 ; 24 ;-12)$ from T0 to T1 correlates with SPQ score at the 8-year follow-up.

up is in agreement with previous studies finding similar associations in the short term $[4,5]$. The anterior insula has been implicated in extinction learning [6], the neural process upon which exposure therapy relies. The posttherapy scanning session can be regarded as equivalent to recall of extinction learning: insufficient reduction of insular activation from the pre- to posttherapy time point could reflect that extinction learning, its consolidation or generalization was not optimal/maximized. The anterior insula and lateral orbitofrontal cortex have also been involved in evaluating affective states and cues, with the anterior insula being more specifically implicated in interoception [2, 7]. Normalization of its activity suggests a reduction in the subjective experi- 
ence of phobic fear and arousal that is essential for long-term outcome.

A limitation of the study is that it has an uncontrolled design: we did not include a control group or take into account additional factors that might influence long-term exposure therapy outcome. Furthermore, as we did not include MRI scanning at the follow-up, we could not investigate whether the neural results were long lasting. Lastly, the study would provide us more insight into the neural substrates of the therapy process if we added a fear-conditioning and extinction paradigm including a recall phase to the study design [8].

Despite these methodological considerations, the results of the present study warrant a focus on the insula/lateral orbitofrontal cortex in future studies into the neural effects of psychological therapy. Finally, they underscore the potential value of neuroimaging in understanding heterogeneity in long-term therapy effects, leading to treatment optimization and improving clinical outcome.

\section{Disclosure Statement}

The authors declare that they have no conflicts of interest.

\section{References}

1 Vervliet B, Craske MG, Hermans D: Fear extinction and relapse: state of the art. Annu Rev Clin Psychol 2013;9:215-248.

- 2 Goossens L, Sunaert S, Peeters R, Griez EJ, Schruers KR: Amygdala hyperfunction in phobic fear normalizes after exposure. Biol Psychiatry 2007;62:1119-1125.

- 3 Craske MG, Kircanski K, Zelikowsky M, Mystkowski J, Chowdhury N, Baker A: Optimizing inhibitory learning during exposure therapy. Behav Res Ther 2008;46:5-27.

4 Linares IM, Chags MH, Machado-de-Sousa JP, Crippa JA, Hallak JE: Neuroimaging correlates of pharmacological and psychological treatments for specific phobia. CNS Neurol Disord Drug Targets 2014;13: $1021-1025$

5 Cisler JM, Steele JS, Lenow JK, Smitherman S, Everett B, Messias E, Kilts $\mathrm{CD}$ : Functional reorganization of neural networks during repeated exposure to the traumatic memory in posttraumatic stress disorder: an exploratory fMRI study. J Psychiatr Res 2014;48:47-55.

-6 Sehlmeyer C, Schöning S, Zwitserlood P, Pfleiderer B, Kircher T, Arolt V, Konrad C: Human fear conditioning and extinction in neuroimaging: a systematic review. PLoS One 2009;4:e5865.

7 Milad MR, Rauch SL: The role of the orbitofrontal cortex in anxiety disorders. Ann NY Acad Sci 2007;1121:546-561.

8 Lueken U, Straube B, Konrad C, Wittchen H-U, Ströhle A, Wittmann A, Pfleiderer B, Uhlmann C, Arolt V, Jansen A, Kircher T: Neural substrates of treatment response to cognitive-behavioral therapy in panic disorder with agoraphobia. Am J Psychiatry 2013;170:1345-1355. 